\title{
Fine structure of breakup development inferred from satellite and ground-based observations
}

\author{
T. A. Kornilova, I. A. Kornilov, and O. I. Kornilov \\ Polar Geophysical Institute, Apatity, 184209, Russia
}

Received: 27 February 2007 - Revised: 21 September 2007 - Accepted: 21 September 2007 - Published: 28 May 2008

\begin{abstract}
More than 60 breakups, including weak activations of the pseudo-breakup type, moderate breakups, and events of very strong auroral activity, were analyzed using ground-based TV data, together with satellite auroral images. We studied the fine subvisual details of spatial and temporal dynamics of active auroral forms and surrounding diffuse luminosity, both in the longitudinal and latitudinal directions of the TV camera field of view. For all types of breakups a close interconnection of auroral activity was found across and along the auroral oval.
\end{abstract}

Keywords. Magnetospheric physics (Auroral phenomena; Magnetosphere-ionosphere interactions; Magnetotail)

\section{Introduction}

The problem where the main processes responsible for a substorm onset are located (in the near-Earth neutral line (NENL) region or near the inner edge of the plasma sheet) is very important for understanding aurora physics and has been discussed for many years (Elphinstone et al., 1996; Lui, 2001, and references therein). All present substorm models can be grouped into two types: the convection-braking type and the current-disruption instability type. According to the first type of models, for example, the NENL model (Baker et al., 1996; Shiokawa et al., 1998; Kan, 2007), substorm onset occurs 20-30 $R_{E}$ down-tail as a consequence of the reconnection process. The current disruption $(\mathrm{CD})$ model (Lui et al., 1996, 2001) predicts the substorm current wedge to develop as a result of an instability in the cross-tail current, with the onset location being at about $6-10 R_{E}$. However, neither one of the models nor their syntheses could explain completely the substorm phenomenon, especially its onset, which is most visibly manifested in the ionosphere

Correspondence to: T. A. Kornilova

(kornilova@pgi.kolasc.net.ru) as the auroral breakup. Available experimental data confirm aspects of both of the above-mentioned types of models. Some ground-based and geostationary observations (e.g. Ohtani et al., 1999, and references therein) suggest that the very first intensification occurs at the equatorial boundary of the plasma sheet. Other observations lead to the conclusion that a substorm expansion onset is triggered by magnetic reconnection which initially takes place at $\sim-20 R_{E}$ (see, e.g. Miyashita et al., 2000) or nearer (Petrukovich and Yahnin, 2006) in the pre-midnight sector . A few minutes later, dipolarisation occurs around $\mathrm{X} \sim-10 R_{E}$, simultaneously with a substantial plasmoid evolution in the region of $-23>\mathrm{X}>-30 R_{E}$.

Perhaps the first convincing facts and ideas about the key role of close interaction between the two regions mentioned above (15-20 $R_{E}$ and 6-10 $R_{E}$ ) for breakup development could be found in Voronkov et al. (2004). According to their findings, energy stored in the magnetotail during the substorm growth phase can be locally released in the form of auroral breakups or local substorms, which can be triggered both internally (e.g. development of some local instability) and externally (by solar wind magnetic field changes or as a result of earthward travelling perturbations of the more distant magnetotail). However, the character and sequence of the signatures for internally and externally triggered breakups are the same. Full substorm onset is a combination and interaction of the inner edge breakup and more distant (NENL) tail disruption, and both processes play an essential role. Interaction can be initiated by both the midtail and near-Earth breakup activations, although the interactions between them and the causal sequence of events have not been clarified.

In this paper we present a study of the fine structure and dynamics of auroral arcs and the surrounding diffuse luminosity, both in the longitudinal and latitudinal directions before the auroral breakup in the spatio-temporal vicinity of the auroral breakups by using auroral TV data. 


\section{Data used, instrumentation and data processing}

For the study we use an analog SIT-vidicon TV camera with a Nikon all-sky lens (1:2.8, field of view 180 degrees). The camera usually operates in integral light, spectral range $4000-8000$ angstroms, with a maximum sensitivity of about 5000 angstroms. The video output is a normal TV signal (interlaced 50 fields or 25 frames per second, 625 lines per frame), and therefore can be recorded by an ordinary VHS video recorder. Afterwards, we digitize the recorded signal from the videotape ( 8 bits, $320 \times 240$ pixels, 25 frames per second). We can also record the TV signal by DVD recorder, and this is very convenient for the ordinary, every day digital data collecting and initial selection of interesting aurora events (special software allows us very fast direct IDLprocessing of DVD video files), but because we use MPEG2 data compression in the DVD recording process there is a danger of artifacts, and thus we do not use the DVD for investigation of fine subvisual aurora details. Analog camera and analog recording have a great advantage of preserving the smallest aurora intensity variations, even if some stochastic noise added by the video recorder is take into account (using a digital TV camera everything less than 1 bit is definitely lost, absolutely and forever), and we can digitize recorded data many times in different modes (for example, almost arbitrary to amplify the analog TV signal and choose the levels of black and white before digitizing). For TV data integration (summarizing frames) for noise suppression and broadening of the dynamic range of the data, many effective methods of image filtering and enhancement are widely used, as well; some of them are briefly presented in the Appendix. These methods allow one to reveal and study very weak and fine aurora details with characteristic luminosity less than 0.01 percent of the average auroral arc intensity. An animation of integrated and, if necessary, filtered frames (frames obtained during $1-10 \mathrm{~s}$, that is $25-250$ frames are summarized in one) is very useful. The resulting film has a good dynamic range, is strongly time compressed, and reveals a lot of fine, slowly moving, subvisual auroral structures (for example, 3-5 satellites moving in different directions can be seen simultaneously in the all-sky movie).

Experimental data used in this study were the following:

- To investigate the fine structure of auroras we used the auroral TV data from Lovozero located at $\Lambda=63.99^{\circ} \mathrm{N}$, $\Phi=114.87^{\circ} \mathrm{E}$ ( $\Lambda$ and $\Phi$ are corrected geomagnetic latitude and longitude, respectively). The difference between local time and UT at Lovozero is $2 \mathrm{~h} 34 \mathrm{~min}$.

More than 60 breakups, including weak activations of the pseudo-breakup type, moderate breakups and events of very strong auroral activity were analysed.

- Data from the Scandinavian International Monitor for Auroral Geomagnetic Effects (IMAGE) chain of ground magnetometers, located at approximately a fixed magnetic longitude, whose magnetic midnight is at $\sim 21: 30$ UT, were used to judge the geomagnetic conditions.

- The global auroral images used in this study were obtained from the satellites POLAR and IMAGE. Unfortunately, spacecraft auroral data were available only for 17 events of the total set of auroral breakups.

\section{Observations}

3.1 Weak auroral activity of pseudo-breakup type (18 events)

A typical event of the pseudo-breakup type is represented in Fig. 1, which shows a sequence of TV frames on 23 December 2000 at 20:30-21:30 UT (A), N-S and E-W filtered keograms for Lovozero TV data (A1 and A2, respectively), ground magnetometer data for the 18:00-24:00 UT time interval (B), contrast-enhanced IMAGE satellite auroral plots for the whole oval (C), and enlarged sections (C1).

In Fig. 1 (A) one can see a weak, quiet pre-breakup arc in zenith (20:30-21:13 UT), accompanied by auroral activity to the north. White arrows in the TV frames indicate the direction of motion of the auroral forms and luminosity inhomogeneities. The breakup began at 21:12 UT at the western edge of the pre-breakup arc. The keogram N-S demonstrates auroral forms moving from the north at the speed of about $100-150 \mathrm{~m} / \mathrm{s}$ before the breakup. The false pulsations in the bottom of the N-S keogram (A1) are artifacts caused by changing the digits of the TV timer. The keogram (A2) shows an E-W motion along the oval of auroral forms with a speed of about $300-500 \mathrm{~m} / \mathrm{s}$. We do not consider the northern arc brightening around 21:07 UT as a pseudo-breakup; we analyse auroral activity occurring at the most equatorward arc. Besides, no magnetic pulsations were detected by the Lovozero magnetometer at 21:07 UT.

Data of the Scandinavian magnetometer chain shown in Fig. 1 (B) reveal only small magnetic field variations at the moment of the breakup at about 21:12 UT, marked by the arrow $T_{0}$. Moreover, the poleward expansion during this auroral activation was not large, so we assume the event to be a pseudo-breakup. The major breakup occurred somewhat later, at about 22:20 UT.

The enlarged sections of IMAGE satellite pictures show the aurora development above the Kola Peninsula. Prior to the pseudo-breakup at Lovozero (21:12:32 UT), a small auroral spot marked by arrows in the IMAGE satellite plots at 21:06:24 and 21:12:32 was observed at $200-250 \mathrm{~km}$ to the north of Lovozero. This spot intensified before the pseudobreakup and faded after it. Southward movement of the spot is seen both in the IMAGE spacecraft plots and keogram (A1) in the form of fine structures moving towards the pre-breakup arc. Keogram (A2) demonstrates subvisual structures moving westwards along the auroral oval before the breakup. 


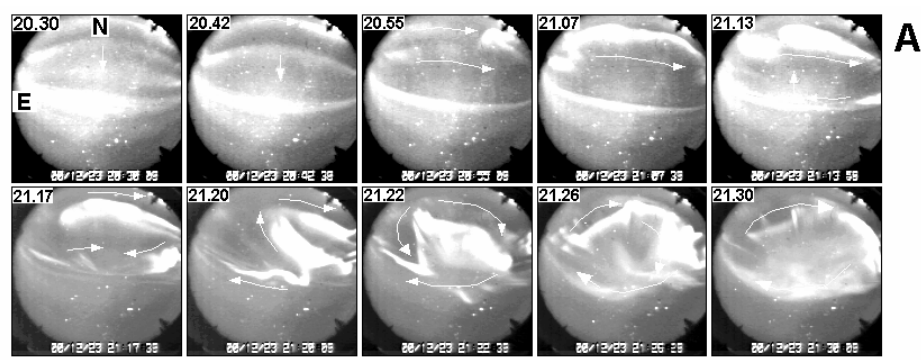

A
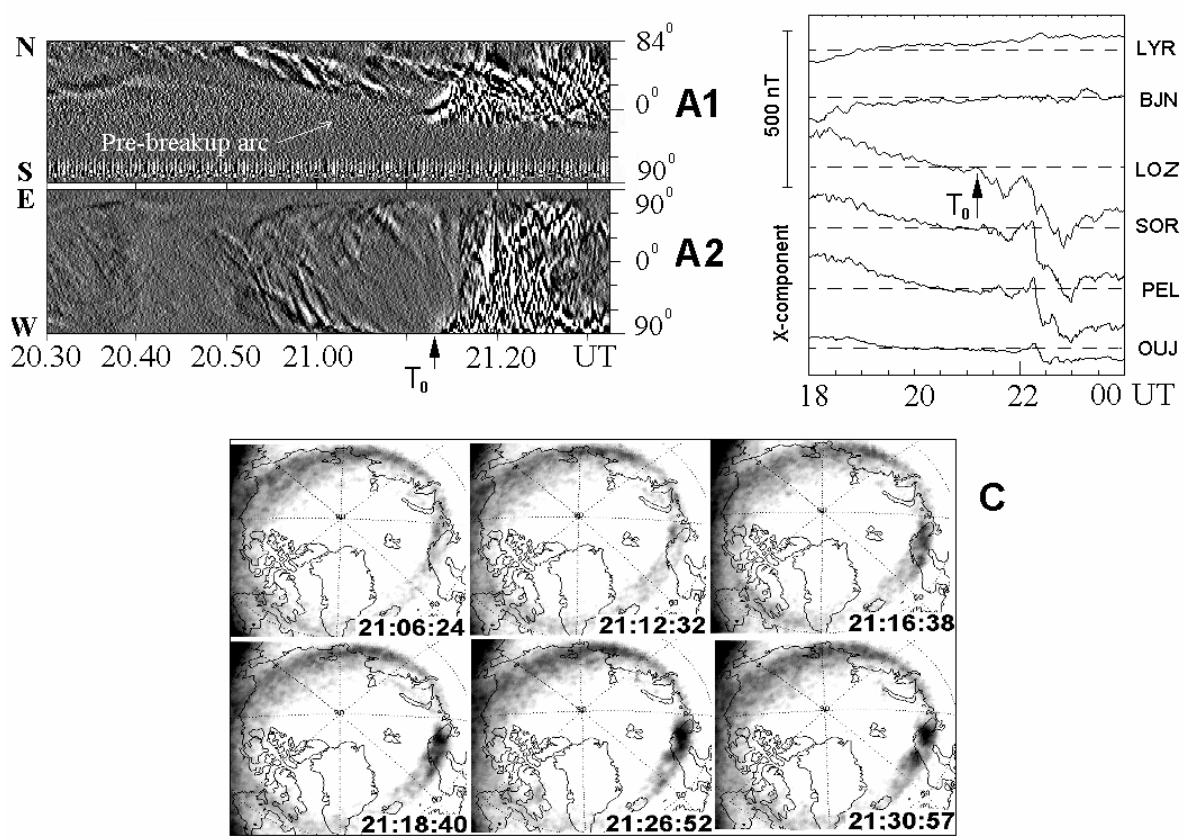

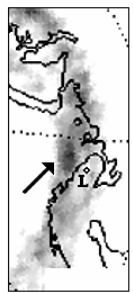

$21: 06: 24$

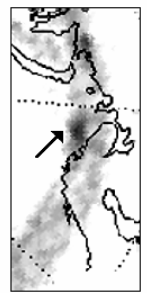

$21: 12 \cdot 32$

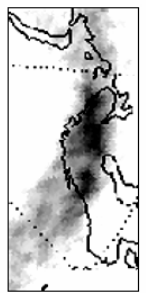

$21: 16 \cdot 38$

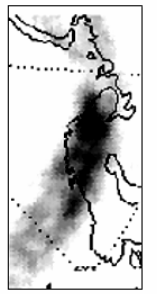

$21: 18 \cdot 40$

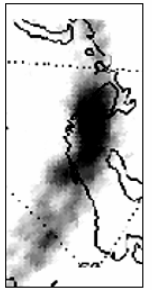

$21: 26: 52$

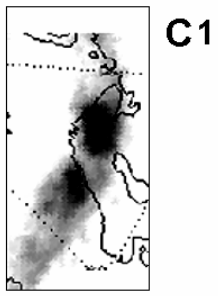

21:30:58 UT

Fig. 1. Sample of data for weak auroral activity of a pseudo-breakup type on 23 December 2000.

Shown are: TV original frames (A), universal times are indicated in the left top corner of each frame; filtered keograms from Lovozero in the North-South (A1) and East-West (A2) direction, vertical scale to the right of the keograms is the zenith angle given in degrees, $T_{0}$ marks a breakup onset; and the geomagnetic field X-component recorded by IMAGE magnetometer network stations (B); contrast enhanced auroral images from the IMAGE spacecraft $(\mathbf{C})$, and enlarged sections $(\mathbf{C 1})$, the location of Lovozero is indicated by a circle and the letter "L" in the leftmost panel of the IMAGE spacecraft image.

From the IMAGE plots of the whole oval, we conclude that theses structures originated from a substorm recovery phase activity above Siberia (probably, pulsating aurora).

It is worthwhile to note one interesting feature seen both in the keogram of Fig. 2 (A2, A4), Fig. 1 (A1) and all other events we have analysed. The breakup begins when some fine subvisual auroral structures approach the pre-breakup arc.

\subsection{Moderate breakups (30 events)}

Figure 2 presents an example of moderate auroral activity that occurred on 26 December 2000 at Lovozero. Again, TV frames (A), original (A1) and filtered (A2) keograms in the figure indicate auroral activity to the north and a pre-existing growth phase arc in zenith of Lovozero. The breakup started at 20:34 UT. Magnetograms (B) show a negative excursion 


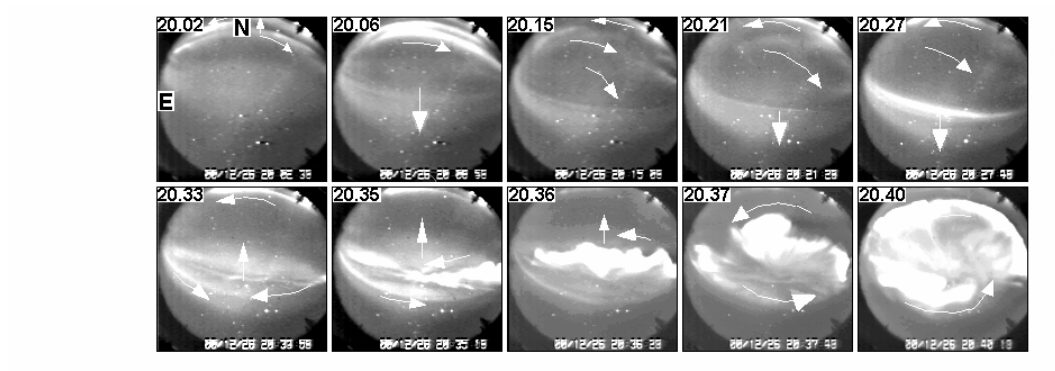

A
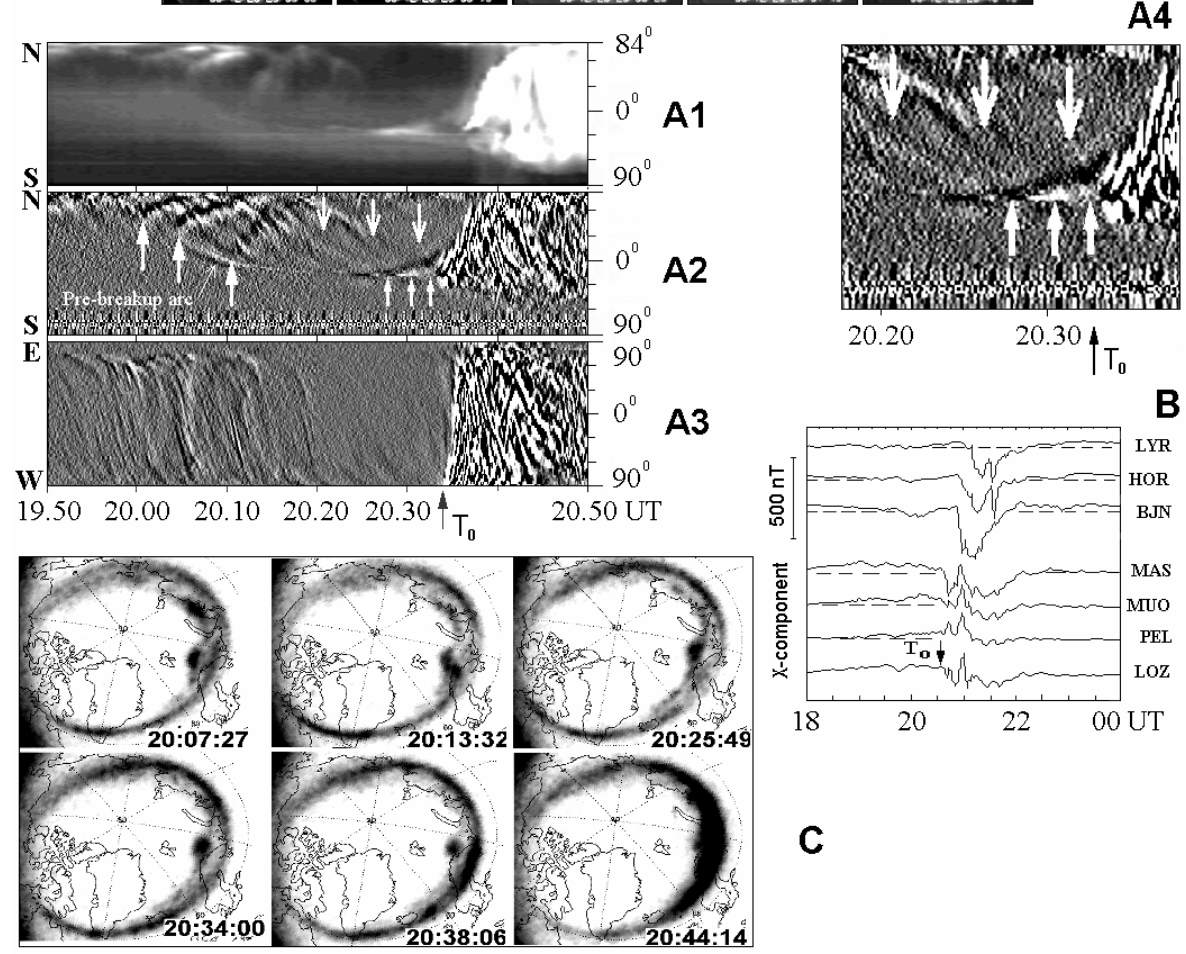

A3

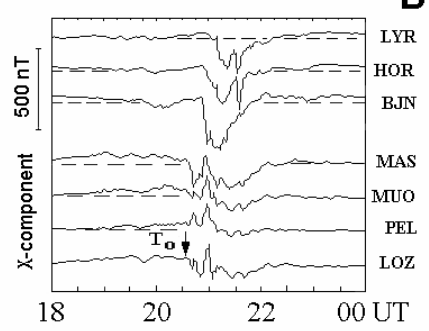

C

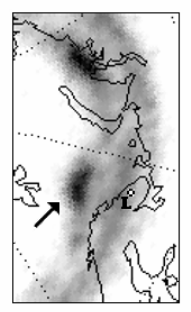

$20: 07: 27$

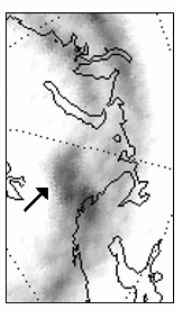

$20: 13: 32$

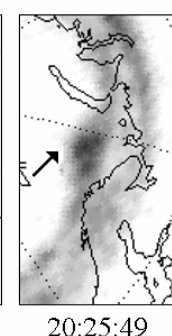

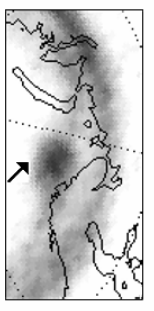

20:34:00

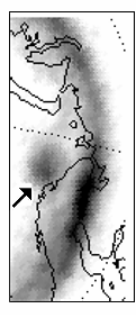

20:38:06

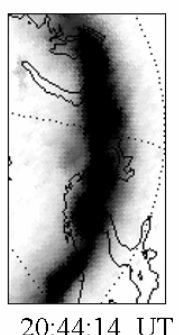

\section{1}

Fig. 2. Sample of data for a moderate breakup that occurred on 26 December 2000. Panels (A), (B), (C), (C1) are the same as in Fig. 1. Panel (A1) is an original keogram from Lovozero; (A2) and (A3) are North-South and East-West filtered keograms; (A4) is an enlarged section of the keogram (A2) demonstrating auroral dynamics in the vicinity of the breakup.

Three groups of white arrows in the filtered keogram (A2) indicate three kinds of auroral structures invisible in the original keogram (A1), these structures show a relation between auroral activity across the auroral oval and are probably breakup precursors.

in the X component of the geomagnetic field variations related to this breakup. Unlike the case of the pseudo-breakup, the IMAGE spacecraft plots (C) show that the auroral distribution has the double oval form. By analysing many IMAGE pictures we can assume that the phenomenon of the double oval itself is a result of periodic activations at the southern part of the oval, and the multiple sporadic ap- pearance of auroral spots to the north (in the previous case of a pseudo-breakup, and weak activity along the oval, we can see this phenomenon in an isolated individual form). Panel (C) shows two spots of pre-breakup aurora at the poleward boundary of the double oval, $500 \mathrm{~km}$ to the north from the main oval. Prior to breakup we can see the fading of the northern spot. Keograms (A2) and (A3) also demonstrate 


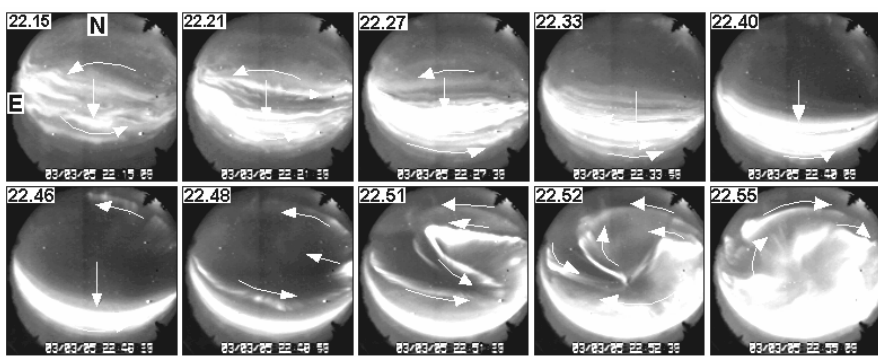

A
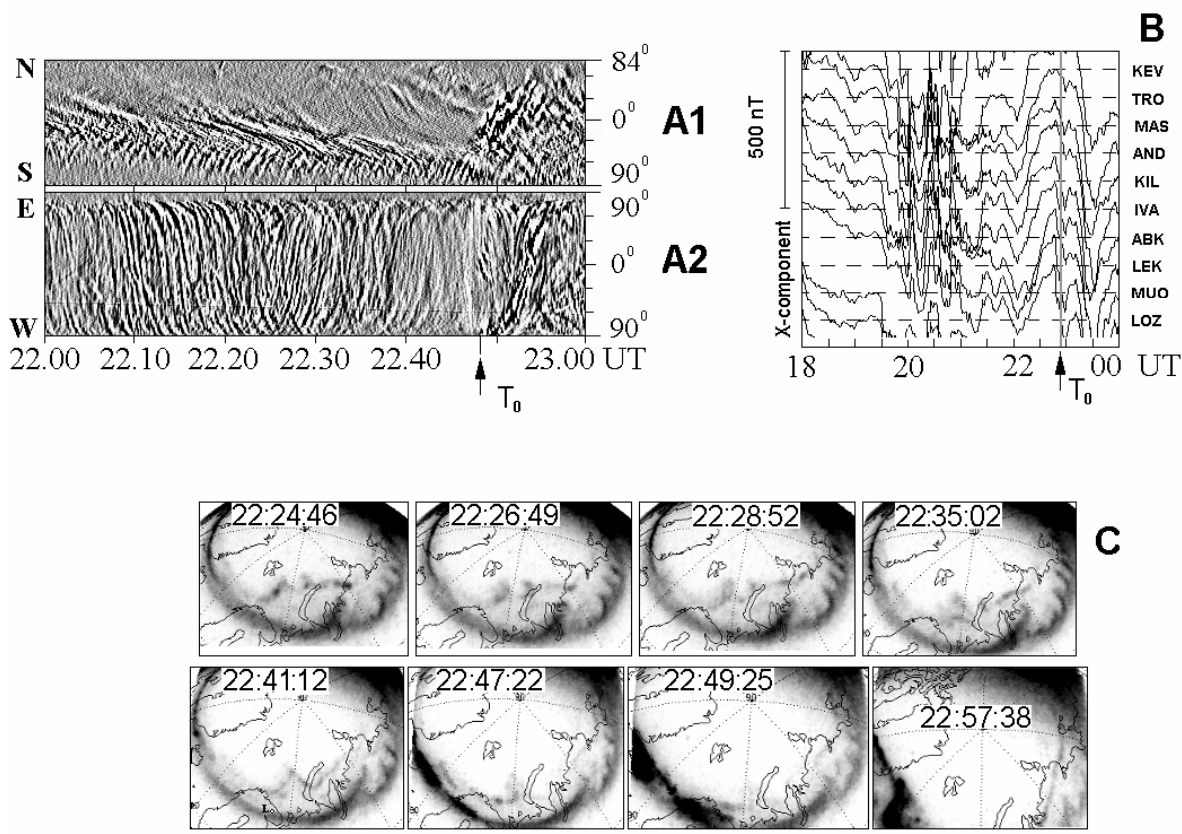

Fig. 3. Sample of data for a strong auroral activity event on 5 March 2003.

Panels (A), (A1), (A2), (B) are the same as in Fig. 1, panel (C) has auroral images from the IMAGE spacecraft. Universal times are indicated in each auroral plot.

a very close interaction of events, both across and along the oval. Note in Fig. 2 (A2) periodic (period about 5$7 \mathrm{~min}$ ) wave-like auroral form motions from the southern prebreakup arc to the north (20:00-20:20 UT) intensify activity at the northern horizon, pointed out by upward arrows. In turn, subvisual structures drifting from north to south approach the pre-breakup arc, (downward arrows at 20:1520:34 UT) and activate it. Three upward arrows at 20:2520:34 UT in the keogram (A2), as well as in its enlarged section (A4), signify weak pulsating arcs splitting from the prebreakup arc and drifting poleward. Unfortunately, this effect is difficult to see in the presented frames and keograms, but it is well visible in the film, i.e. the animation of integrated frames. Figure 2 (A3) also demonstrates weak subvisual auroral structures moving from east to west along the auroral oval before the breakup. For this time interval IMAGE pictures of the whole oval (C) show noticeable auroral activity east of the Kola Peninsula.

\subsection{Strong auroral activity (12 events)}

Figure 3 shows an event of very strong auroral activity expanding over the whole oval. Unfortunately, the altitude of the IMAGE satellite was too low during the time interval of interest, so the whole oval cannot be seen in the plots. Nevertheless, one can see in Fig. 3 (C) active auroral forms 500$600 \mathrm{~km}$ north of the main oval, and well-pronounced omegastructures somewhere above Siberia. It should be noted that in this case the pre-breakup arc emerged within the region of pulsating aurora related to the previous activity (Fig. 3 (A)). The breakup onset at Lovozero at 22:47 UT was preceded by many hours of strong disturbances recorded by stations of the IMAGE magnetometer network (Fig. 3 (B)). The vertical line indicates the starting time of the breakup at Lovozero.

Auroral dynamics during strong activity events is more complicated as compared to the cases of pseudo- and moderate breakups. The N-S keogram (A1) indicates very intensive pre-breakup aurora motions in both the N-S and S-N 
directions (22:00-23:00 UT), and these structures move towards each other. Continuous and intense auroral forms travelling in both the E-W and W-E directions along the oval are presented in keogram (A2). Though aurora dynamics in the case of strong magnetic disturbances is rather complicated, the tendency of a close interaction between different regions of auroral activity along and across the oval is obvious.

\section{Discussion}

Previously, a correlation of auroral luminosity between northern and southern parts of the oval on time scales from tens of minutes to about ten seconds has been found by detailed cross-correlation analysis of photometered groundbased TV data (Kornilov et al., 2000). The authors assumed that the physical reason for the correlation at small time scales could be weak electron precipitation driven by MHD waves, travelling away from the active region of the magnetosphere. Our study of TV data and satellite images for different types of breakup shows intensive motion of subvisual auroral structures, both across and along the auroral oval before the breakup onset (filtered keograms in Figs. 1-3), and this fact demonstrates a close correlation and interaction of auroral events inside the oval. Moreover, these moving structures stimulate breakup development when they come into contact with the pre-breakup arc, and this fact rejects their ionospheric origin. Auroral dynamics is an ionospheric projection of the processes developing inside the magnetosphere, so interaction of auroral structures means interaction and interconnection of different regions of the magnetosphere. A detailed examination of the filtered keograms and TV frames animation allowed us to see several kinds of well-defined subvisual structures drifting from different parts of the oval to the pre-breakup arc some minutes before the breakup onset:

1. Subvisual structures drifting southward to the prebreakup arc (white downward vertical arrows in the filtered keogram N-S of Fig. 2 (A2)).

2. Weak pulsating arcs splitting from the pre-breakup arc and drifting poleward (white upward vertical arrows in the filtered keogram N-S of Fig. 2 (A2)).

3. Auroral waves spreading along the pre-breakup arc with the period 1-2 min and the speed from $200 \mathrm{~m} / \mathrm{s}$ to some $\mathrm{km} / \mathrm{s}$ along the oval (filtered E-W keograms in Figs. 1, 2).

4. Auroral pulsations with the period $10-70 \mathrm{~s}$ in the diffuse luminosity equatorward of the pre-breakup arc (for details, see Kornilova et al., 2004).

Zooming in on filtered keograms and TV animations shows that the auroral breakup is stimulated by auroral activity coming to the future breakup location from northern regions of the oval. Several minutes before the breakup onset some subvisual structures approach the pre-breakup arc, and we assume that these structures may be considered as breakup precursors. Their combined influence stimulates a breakup onset, provided the region where interaction occurred is ready for the explosive process. Vertical white arrows in the filtered keogram N-S of Fig. 2 (A1) at 20:15-20:34 UT and at 20:25-20:34 UT indicate such precursor structures.

A very important issue is the question about what regions of the magnetosphere interact in the north-south direction, i.e. where in the magnetosphere the northern spot in the satellite oval images, and where the breakup in the southern part of the oval should be projected. Rostoker (Rostoker, 1996) argued that there are two aurorally active regions: one near the high-latitude edge of the evening sectors of the oval and the other near the equatorward edge of the midnight and morning sector of the oval. These regions are connected with processes near the inner edge of the plasma sheet and in the more distant tail. All aurora data analyzed in our paper are consistent with this statement. According to Rostoker (1996), more distant tail processes are associated with velocity shear zones and possibly boundary layer physics, while Pulkkinen et al. (1998) associate processes in the more distant tail with magnetic reconnection. Taking into account their results, we suggest that the observations in our data of weak visual and subvisual structures moving from one region of the oval to another and intensifying them, manifest a relationship between different regions of the auroral oval and, therefore, a close interaction between the processes occurrs in the tail reconnection region and in the near magnetotail.

Following the results of Elphinstone et al. (1995), suggesting that the most poleward part of the double oval may be linked to reconnection processes in the magnetotail tailward of $\mathrm{X}=-28 R_{E}$ and taking into account the findings of Nagai et al. (2005), according to which the location of the reconnection site in the magnetotail is controlled by IMF and solar wind velocity, we assume that the northern activity is related to NENL and is controlled by solar wind conditions.

As known (Rostoker et al., 1996; Lui, 2001, and references therein), the near-Earth processes are mapped to the equatorward edge of the oval. At the same time our data give evidence that a breakup onset is stimulated by activity coming from other regions of the oval (Figs. 1,2), and can be related to the preceding auroral activity (Fig. 3). This allow us to consider that the breakup is definitely a result of a close interaction between more distant magnetosphere tail processes $\left(20-30 R_{E}\right)$ and events in the inner magnetosphere $\left(6-8 R_{E}\right)$. Using a crude analogy, we can compare the breakup to a thunderstorm, the latter being defined as a local phenomenon, nevertheless is prepared by a complicated chain of atmospheric circulation processes over a very large territory. 


\section{Conclusion}

Using TV auroral data from Lovozero and auroral images from POLAR and IMAGE we have examined the relation between auroral activity in the different parts of the auroral oval for 60 breakups which occurred during auroral disturbances of different strength. We have concentrated on the time interval $30 \mathrm{~min}$ before to $20 \mathrm{~min}$ after the breakup onset.

The results of our study show that:

- For all considered types of breakups, permanent and close interactions between different regions of the auroral oval, both in longitudinal and latitudinal directions, take place. The existence of this interaction is confirmed by the fine structure and dynamics of subvisual and weak visual diffuse and discrete auroras.

- The auroral breakup, though it begins as a local process, really is not a purely local phenomenon; it is prepared by a complicated chain of processes occupying large regions of the magnetosphere, including the tail reconnection region and inner edge of the plasma sheet.

- The details of the interaction depend both on magnetospheric conditions at the moment of the breakup and the history of previous activity.

\section{Appendix A}

During the last decades a lot of different methods of image processing, filtering and improvements have been developed for various areas of science and techniques (for robotics, machine vision, radars and sonars, satellites imaginary, X-rays control, medicine tomography and so on). Many of these methods can be successfully used for auroral TV data processing, both for TV frames and keograms, and a lot of weak and fine details of aurora, often absolutely invisible in the initial data, can be revealed and studied. Image defects, due to difficult observational conditions, can be corrected, as well (fog, clouds, disturbing luminosity of twilight and city lights, etc.).

Different convolution filters, as well as filters basing on FFT (Fast Fourier Transform), WTN (Wavelet Transform), SVD (Singular Value Decomposition), Hough Transform, procedures of local contrast intensification, histogram equalization, image transformation on a given histogram pattern, etc., can be used for image filtering and improvement. It is important to note that methods of image improvement can be applied for processing not only TV information, but also many other types of geophysical data. Scanning photometer keograms, EISCAT and satellite tomography pictures of ionosphere plasma concentration, energy-time spectrograms of data from particle detectors on satellites, VLF and magnetic pulsations frequency spectra, and in general any information, which can be presented in a two-dimensional form,
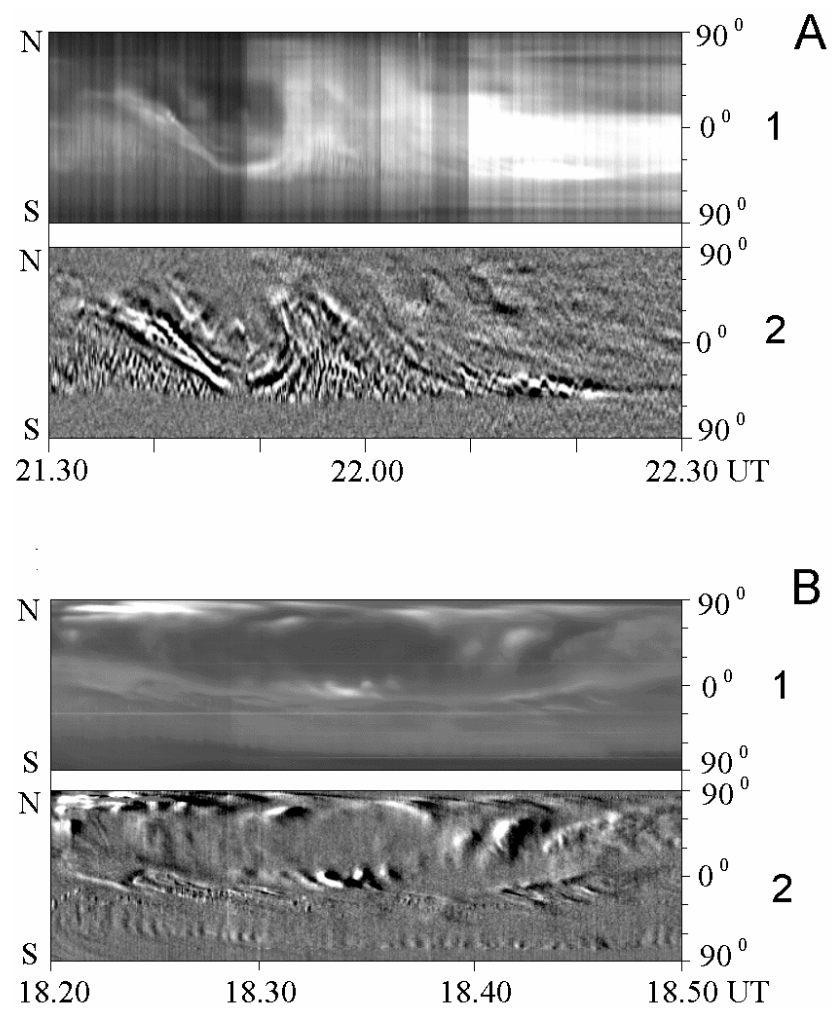

Fig. A1. Using gradient filtering for keogram processing.

Suppression of TV camera technical defects and fog. Lovozero, 10 December 1998 (A). Detection of high-frequency auroral pulsations in the zenith, and low-frequency pulsations at the border of diffuse luminosity. Lovozero, 8 February 1997 (B).

Panels (A1 and B1) are initial keograms, panels (A2 and B2) are gradient filtered keograms.

i.e. as an image, can be successfully processed and enhanced (Kornilov et al., 2004).

For TV keogram processing we often (and in this paper exclusively) use the very simple, fast and effective method of so-called gradient image filtering. Actually gradient filtering is a result of the simple subtraction of the initial keogram matrix and the same matrix, shifted in a vertical or horizontal direction by the desired number of pixels (both shifts can be used in different combinations). This procedure transforms an ordinary keogram to a picture of time (for horizontal gradients) or space (for vertical gradients) derivatives. If, for example, we have an initial keogram in the north-south direction, vertical (space) gradients strongly emphasise auroral structures moving in N-S or S-N directions, and horizontal (time) gradients reveal weak temporal auroral luminosity variations. To reduce the increasing image noise, some wellknown methods of smoothing, sliding averaging, SavitzkyGolay smoothing and statistical Lee-filtering procedures can also be used. 
Despite its simplicity, gradient filtering is very effective for revealing the fine details of keograms, often invisible in initial data, due to TV camera defects or bad observational conditions; Fig. A1 (A) presents an example. The poor stability of the camera's black level results in a strong and chaotic modulation of keogram brightness. Besides, a rather strong fog accompanied the presented time interval, especially after 21:50 UT. Nevertheless, the application of gradient filtering allows for many details to be revealed, in particular, intense auroral pulsations (period about 10-20 s). These pulsations occur southward of the diffuse band and are practically invisible in the initial data. Figure A1 (B) shows an example in which different weak subvisual pulsating structures are revealed.

Acknowledgements. The authors are grateful to the PGI for TV aurora data from Lovozero, to the Finnish Meteorological Institute, which maintains the IMAGE magnetometer array, the data providers S. Mende at UC/Berkely/SSL, L. A. Frank at The University of Iowa, G. Parks at U. Washington and CDAWeb for the IMAGE and ROLAR spacecraft aurora data. This research was supported by the Nordic Council of Ministers through grant 08704360105, Network for Groundbased Optical Auroral Research in the Arctic Region, and by the Norwegian Science Council grant number $178911 \backslash$ S30 NORUSCA. This study was also supported by the Programme of Presidium of RAS N 16 and by the Russian Foundation for Basic Research, grant 05-05-64495a and grant 06-05-64374a. The authors would like to thank referees for helpful suggestions.

Topical Editor U.-P. Hoppe thanks I. Sandahl and K. Shiokawa for their help in evaluating this paper.

\section{References}

Baker, D. N., Pulkkinen, T. I., Angelopoulus, V., Baumjohann, W., and McFerron, R. L.: Neutral line model of substorms: past results and present view, J. Geophys. Res., 101(A6), 12975$13010,1996$.

Elphinstone, R. D., Hearn, D. J., Cogger, L. L., Murphree, J. S., Wright, A., Sandahl, I., Ohtani, S., Newell, P. T., Klumpar, D. M., Shapshak, M., Potemra, T. A., Mursula, K., and Suavaud, J. A.: The double oval UV auroral distribution 2. The most poleward arc system and the dynamics of the magnetotail, J. Geophys. Res., 100(A7), 12 093-12 102, 1995.

Elphinstone, R. D., Murphree, J. S., and Cogger, L. L.: What is a global auroral substorm?, Rev. Geophys., 34(2), 169-232, 1996.

Kan, J. R.: On the formationof near-Earth X-line at substorm expansion onset, J. Geophys. Res., 112, A0207, doi:10.1029/2006JA012011, 2007.
Kornilov, I. A., Kornilova, T. A., Pudovkin, M. I., and Kornilov, O. I.: Subvisual auroral waves structures motion and north-south correlations of luminosity inside double oval, Proc. International Conference on Substorm-5, St.Petersburg, Russia, 16-20 May 2000, 303, 2000.

Kornilov, I. A., Kornilova, T. A., Kornilov, O. I.: Fine details of space, time and spectral structure of aurora, VLF-emissions and magnetic pulsations, Auroral phenomena and solar-terrestrial relations, Proceedings of the conference in memory of Yuri Galperin, edited by: Zelenyi, L. M., Geller, M. A., Allen, J. H., CAWSES Handbook-001, 172, 2004.

Kornilova, T. A., Kornilov, I. A., and Kornilov, O. I.: Wave precursors of breakup, Proc. 7th International Conference on Substorms, edited by: Ganushkina, N. and Pulkkinen, T., Helsinki, 2004, 168, 2004.

Lui, A. T. Y.: Current disruption in the Earth's magnetosphere: observations and models, J. Geophys. Res., 101(A6), 13067$13088,1996$.

Lui, A. T. Y.: Current controversies in magnetospheric physics, Rev. Geophys., 39, 535-563, 2001.

Miyashita, Y., Machida, S., Mukai, T., Saito, Y., Tsuruda, K., Hayakawa, H., and Sutcliffe, P. R.: A statistical study of variations in the near and mid-distant magnetotail associated with substorm onset: GEOTAOL observations, J. Geophys. Res., 105, 15 913, doi:10.1029/1999JA000392, 2000.

Nagai, T., Fujimoto, M., Nakamura, R., Baumjohann, W., Ieda, A., Shinonara, I., Machida, S., Saito, Y., and Mukai, T.: Solar wind control of the radial distance of the magnetic reconnection site in the magnetotail, J. Geophys. Res., 110, A09, doi:10.1023/2005JA011207, 2005.

Ohtani, S., Creutzberg, F., Mukai, T., Singer, H., Lui, A. T. Y., Nakamura, M., Pikryl, P., Yumoto, K., and Rostoker, G.: Substorm onset timing: The December 31, 1995 event, J. Geophys. Res., 104(A10), 22 713-22 727, 1999.

Pulkkinen, T. I., Baker, D. N., Frank, L. A., Sigwarth, J. B., Opgenoorth, H. J., Greenwald, R., Friis-Christensen, E., Mukai, T., Nakamura, R., Singer, H., Reevs, G. D., and Lester, M.: Two substorms intensifications compared: Onset, expansion, and global consequences, J. Geophys. Res., 103(A1), 15-27, 1998.

Petrukovich, A. A. and Yahnin, A. G.: The substorm onset location controversy, Space Sci. Rev, 122(1-4), 81-87, doi:10.1007/s11214-006-7022-8, 2006.

Rostoker, G.: Phenomenology and physics of magnetospheric substorms, J. Geophys. Res., 101(A6), 12 995-12 973, 1996.

Shiokawa, K., Baumjohann, W., Haerendel, G., Paschmann, G., Fennell, J. F., Friis-Christensen, E., Luhr, H., Reevs, G. D., Russell, C. T., Sutcliffe, P. R., and Takahashi, K.: High-speed ion flows, substorm current wedge, and multiple Pi2 pulsations, J. Geophys. Res., 103(A3), 4491-4507, 1998.

Voronkov, I. O., Donovan, E. F., Dobias, P., Prosolon, V. I., Jankowska, M., and Samson, J. C.: Late growth phase and breakup in the near-Earth plasma sheet, Proceedings of ICS-7, Helsinki, 140, 2004. 